\title{
Contextual investigation of factors affecting sludge accumulation rates in lined pit latrines within Kampala slum areas, Uganda
}

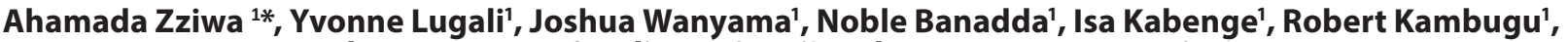 \\ Florence Kyazze ${ }^{2}$, Julia B. Kigozi ${ }^{1}$ and Peter Tumutegyereize ${ }^{1}$ \\ 'Department of Agricultural and Biosystems Engineering, Makerere University, PO Box 7062, Kampala, Uganda \\ ${ }^{2}$ Department of Extension and Innovation Studies, Makerere University, PO Box 7062, Kampala, Uganda
}

\begin{abstract}
Pit latrines in slums areas of Uganda fill up faster than might be expected from some estimates owing to inappropriate use and failure to consider critical factors affecting sludge accumulation rates at the planning, design and construction stages. This study sought to investigate factors affecting filling rates of lined pit latrines in slum areas of Kampala with the goal of contributing to accurate planning, design, construction, emptying and overall maintenance. Fifty-five pit latrines were selected from the five divisions of Kampala city using stratified random sampling. Data collected included: number of users, frequency of emptying, years taken since last emptying, type of non-faecal materials deposited, cross-sectional dimensions of the pit, rate of sludge degradation and geo-physical factors of pit location. Methods used were: field surveys, questionnaires and key informant interviews plus on-site depth measurement. Mass loss tests to investigate the rate of sludge degradation were carried out in the laboratory at moisture content levels similar to those in pit latrines. Sludge accumulation rates were calculated using volume of sludge in the pit, number of users and time taken since last emptying. Statistical analyses included correlation and one-way ANOVA. Results revealed that number of users and type of material deposited in the pit latrines, especially non-faecal matter, had a significant $(p<0.05)$ effect on sludge accumulation rate. Public pit latrines with a higher number of users had lower sludge accumulation rates and this was attributed to greater degradation taking place and greater restriction on entry of non-faecal matter. The rate of sludge degradation was higher at $90-100 \%$ than $80-90 \%$ moisture content, due to better degradation conditions. Tighter restrictions on non-faecal material deposition into pit latrines are recommended to reduce filling rates of pit latrines in slum areas.
\end{abstract}

Keywords: sludge accumulation rates, slum areas, faecal matter, degradation, lined pit latrines

\section{INTRODUCTION}

Pit latrine coverage in Uganda is estimated at $85.5 \%$ (UBOS, 2010). Kampala, Uganda's capital city, hosts the largest part of the country's urban population (Kessides, 2005) with 87\% of the population having access to pit latrines (UBOS, 2012). The majority (46\%) of pit latrines are in a fair condition but about $35 \%$ are in a poor state, either filled up or almost filled up (Zziwa et al., 2014). Despite widespread access, the conditions of the facilities are insufficient and unhygienic due to the large number of users per stance (Nordberg and Winblad, 1994; Grimason et al, 2000; Montgomery, 2007). 'Stance' in the context of Uganda's pit latrines refers to a pit latrine room with one drop hole. There can be more than one pit latrine stance per pit latrine site and this is always the case in rental and school pit latrines for multiple users. This accounts for the poor sanitation situation in the slum areas of Kampala (Fig. 1).

As a result, there is increasing use of plastic bags with faecal matter thrown into drainage channels and commonly referred to as 'flying toilets', and increasing numbers of pit latrines that are abandoned after a relatively short period of time because they are full (Isabel et al., 2011; Zziwa et al., 2016). It is also noted that people who are close to water channels usually open their pit latrines to allow faecal matter to flow into water channels, especially during the rainy season (Kulabako et al., 2007) and this poses water and sanitation challenges in the city. Deteriorating

\footnotetext{
* To whom all correspondence should be addressed.

๘ +256772636253 or +256701636233

e-mail: engzziwa@gmail.com or zziwa@caes.mak.ac.ug

Received 18 July 2015; accepted in revised form 27 June 2016
}

sanitation conditions in the slums arise due to poor pit emptying management and enforcement strategies in Kampala (Oyoo et al., 2011).

Effective pit emptying strategies require a clear understanding of the factors affecting sludge accumulation rates in pit latrines. These include: number of users, use of oxidative chemicals to overcome odour generated from the pits, and deposition of rough papers, plastics, bottles and other nonbiodegradable household refuse (Still and Foxon, 2012). It has been reported that household refuse can contribute, on average, to a $15 \%$ increase in the sludge accumulation rate in pit latrines (Still, 2002). Sludge accumulation rates vary between countries and even within the same country due to differences in climatic and socio-economic factors (Klingel et al., 2002). Individual diets also have a direct influence on the quantity and composition of faeces and urine (Torondel, 2010; WHO, 2004). The proportion of proteins and carbohydrates in each individual's diet might result in different degradation rates and thus affect the accumulation of sludge in a pit (WHO, 2004). In addition to the factors mentioned above, the design of the pit and character of the biological processes within the pit affect the rate at which sludge will accumulate in the pit (Still, 2002).

The biggest challenge in the accurate prediction of sludge accumulation rates in pit latrines in the slum areas is the lack of understanding of these factors, how they relate to each other and their magnitude. This research sought to investigate the factors affecting sludge accumulation rates by studying each factor and its effect on the filling rate. The factors affecting sludge accumulation rate investigated in this paper included: number of users, size of the pit, rate of mass loss due to degradation, type of material deposited in the pit and geo-physical factors of 
the area. The factors were measured on the basis of sludge buildup in the pit latrine. Critical analysis of the factors was done to make an educated approximation as to which factor contributes more to the filling rates in the slum areas of Kampala. An understanding of these factors and how each relates to the other was developed to assist in the prediction of the filling rates of the pit latrines.

\section{METHODS}

\section{Study area}

The study was conducted in Kampala City, which has 5 divisions, namely, Kampala Central, Makindye, Rubaga, Kawempe and Nakawa. This project was carried out in the slum areas of Kamwokya, Luzira, Bwaise, Ndeeba, Banda, Nakulabye, Naguru, Kibuye and Kabalagala, representing all five divisions of Kampala City (Fig. 2).

A total of 55 lined pit latrines were studied including 8 public pits, 6 private pits and 41 rentals. This number was chosen based on a $10 \%$ precision level at $95 \%$ confidence interval whilst taking into account the resources and time available for the study (Israel, 2013). Private pit latrines are those used by a single household; rental pit latrines have limited sharing among tenants and public pit latrines are used by more than 82 users per stance. The pit latrines were randomly selected from each of the five divisions. Ethics clearance was obtained from the Uganda National Council for Science and Technology (UNCST) and permission was also obtained from Kampala Capital City Authority (KCCA) and the local leaders in each of these divisions before the study was carried out. The sampling period was from August 2014 to April 2015.

Pit latrines in the slum areas of Kampala city have unique characteristics that are unlike those observed elsewhere in Africa (Bakare, 2014; Still and Foxon, 2012; Buckley, 2008). The majority of slum areas in Kampala are located in low-lying areas (altitudes between 650-850 m amsl) with high water tables. This means that the majority of pit latrines are shallow (not more than $2.64 \mathrm{~m}$ in depth). There is also frequent flooding especially during the rainy season and this is the reason that the practice of emptying into streams is very common (Kulabako et al., 2007). The slum areas are unplanned informal settlements and therefore the pit latrines in these areas are also not planned. With the exception of the public pit latrines that are built by the city authorities, the other pits are built with varying construction designs and styles. The pits have many users and most of them take on a solid-waste disposal role as well.

\section{Field survey and pit sampling}

A field survey was used to collect information on the number of users for each pit and the frequency of emptying. This information was collected using questionnaires and key informant interviews with pit latrine owners. The type of material deposited in the pit was assessed basing on observation of the pit latrine contents in the pit and as samples were being taken. Some of the materials observed included; faecal matter, polythene bags, sanitary pads, old clothes and diapers. Samples were collected using the pit sludge sampler (Fig. 3). This tool was developed as part of the research specifically for this purpose. It was lowered into the pit latrine, adjusted by pushing the inner handle to ensure that the bottom can is open. The piston was then pulled to suck the entire sample into the sampler. The sampler was removed from the pit latrine and the contents emptied into a sample container
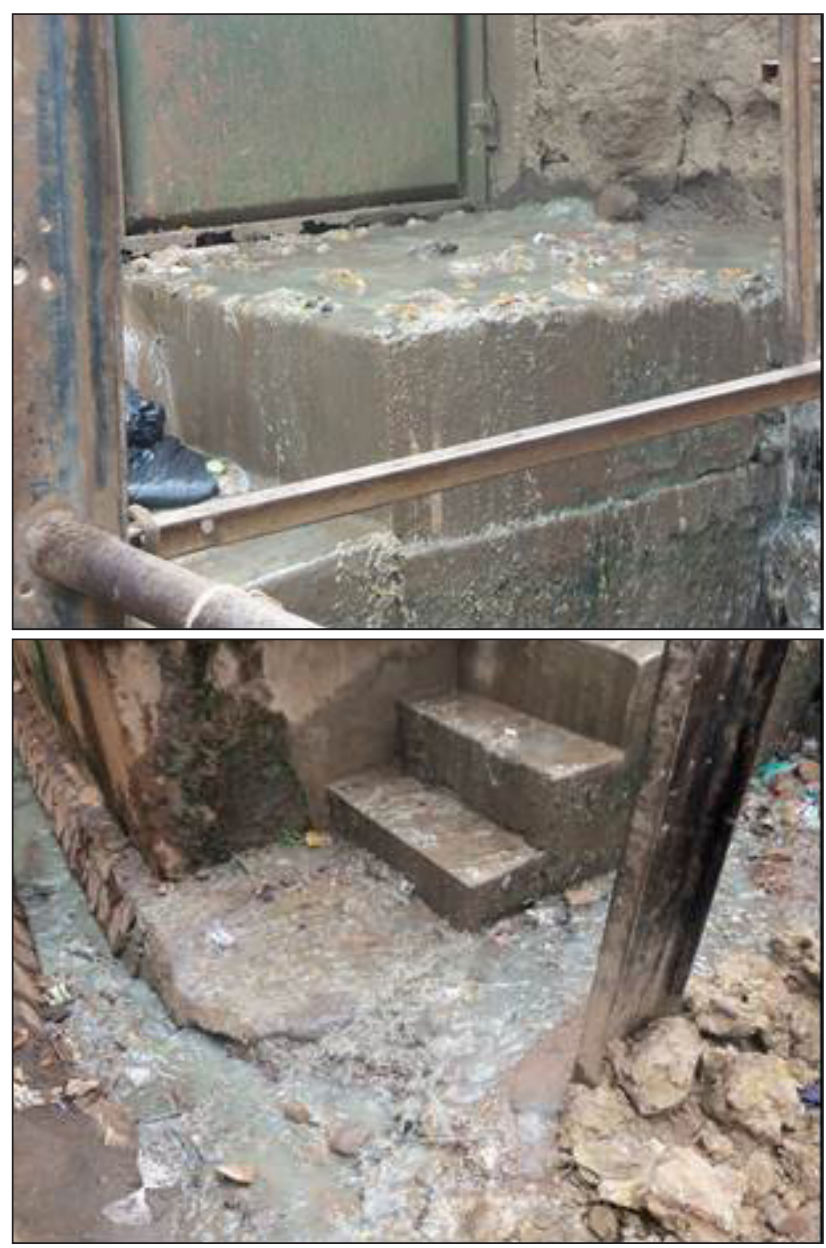

Figure 1

Overflowing pit latrine in Katanga with faecal matter flowing into a drainage channel (Makerere University, 2014)

that was clearly marked with the sample area, date and description of the pit latrine.

Considering the resource limitations of the study, the geophysical factors could not be measured in the field, and this information was obtained from archives in the KCCA offices. The location of each pit latrine was geo-referenced and the altitude recorded. The assumption made in the study was that pits selected in areas with similar geo-physical characteristics were affected in a similar way by these characteristics. The analysis took into consideration the geo-physical characteristics of the location of the pit latrines.

\section{Pit size and depth measurements}

The size of the pit latrine was measured with a tape measure for length and width. The sludge depth was measured using a sludge depth measuring tool purposely developed for monitoring sludge depth changes (Fig. 4). The tool was dipped into the pit latrine and the top layer of the sludge registered a mark on the tool which had a metric ruler attached to it. This reading gave the depth of sludge in the pit latrine.

\section{Laboratory analysis}

The rate of degradation was measured in an experiment that was set up to measure mass loss rates at different moisture content levels; that is, $80-90 \%$ and $90-100 \%$, the moisture content ranges 


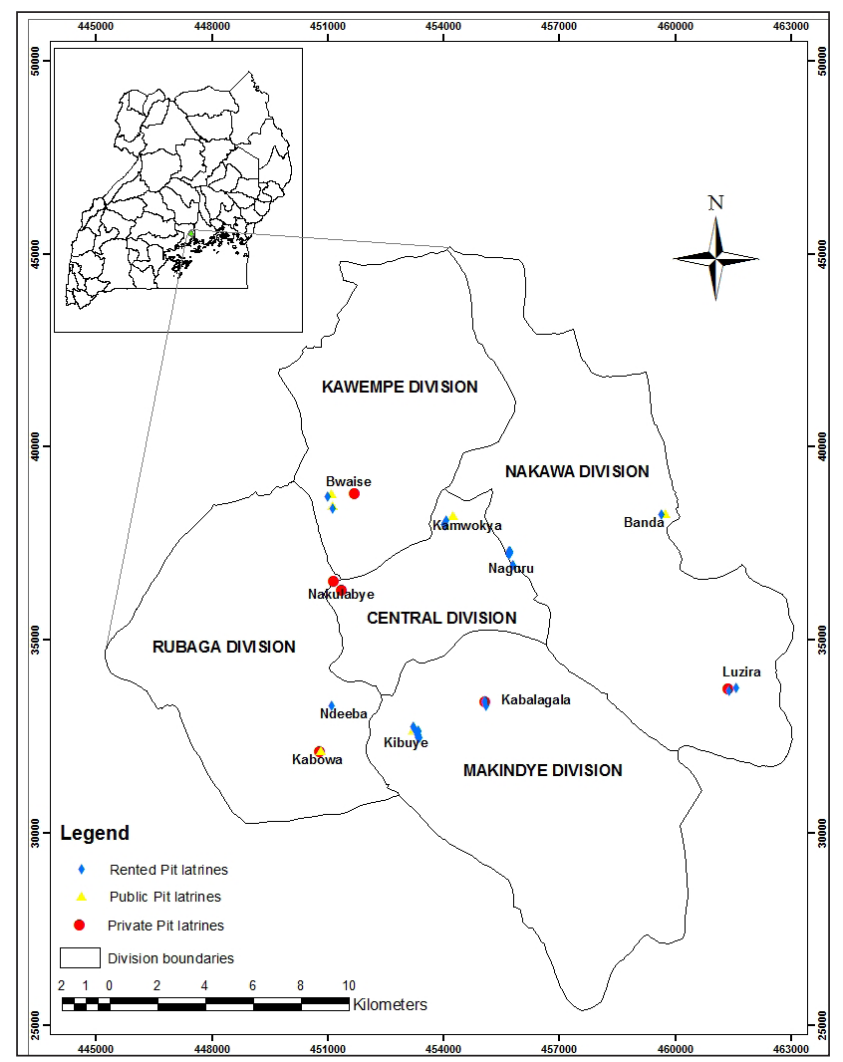

Figure 2

Map of Kampala showing selected pit latrines

found in the sampled pit latrines (Buckley et al., 2008). Six out of the fifteen samples collected during the first phase of the study were randomly selected for this experiment. This was because of the duration of the test ( 3 months) and space requirements for the set-up. A small quantity of each of the selected samples was placed in sealed containers at each of the moisture levels and each sample was replicated 3 times. A control with only water was also set up to cater for the loss due to evaporation. The test was set up for 3 months with mass loss measurements taken weekly. After 3 months the percentage mass loss was computed and used to estimate the rate of degradation in the pit latrines.

\section{Computation of sludge accumulation rates}

Sludge accumulation rates in the slum areas of Kampala City were determined using Mara’s equation (1) (Mara, 1984).

$$
R=\frac{V}{n \times t}
$$

where: $R$ is sludge accumulation rate in $\mathrm{L} \cdot \mathrm{cap}^{-1} \cdot \mathrm{yr}^{-1}, n=$ number of users, $t=$ time taken since last emptying and $V=$ volume of faecal sludge in the pit latrine after time $t$.

Given the number of people who use these pit latrines in the slum areas, these pits are emptied frequently and this made it difficult to continuously monitor a reasonable number of pit latrines. Thus the information used to determine the sludge accumulation rates was collected through key informant interviews with the pit owners and the pit latrine users, who were required to recall the time the pit latrine was last emptied, and the volume of sludge was calculated from the sludge depth and pit dimension measurements. Information on the pit latrines sampled was collected from pit owners or long-term tenants
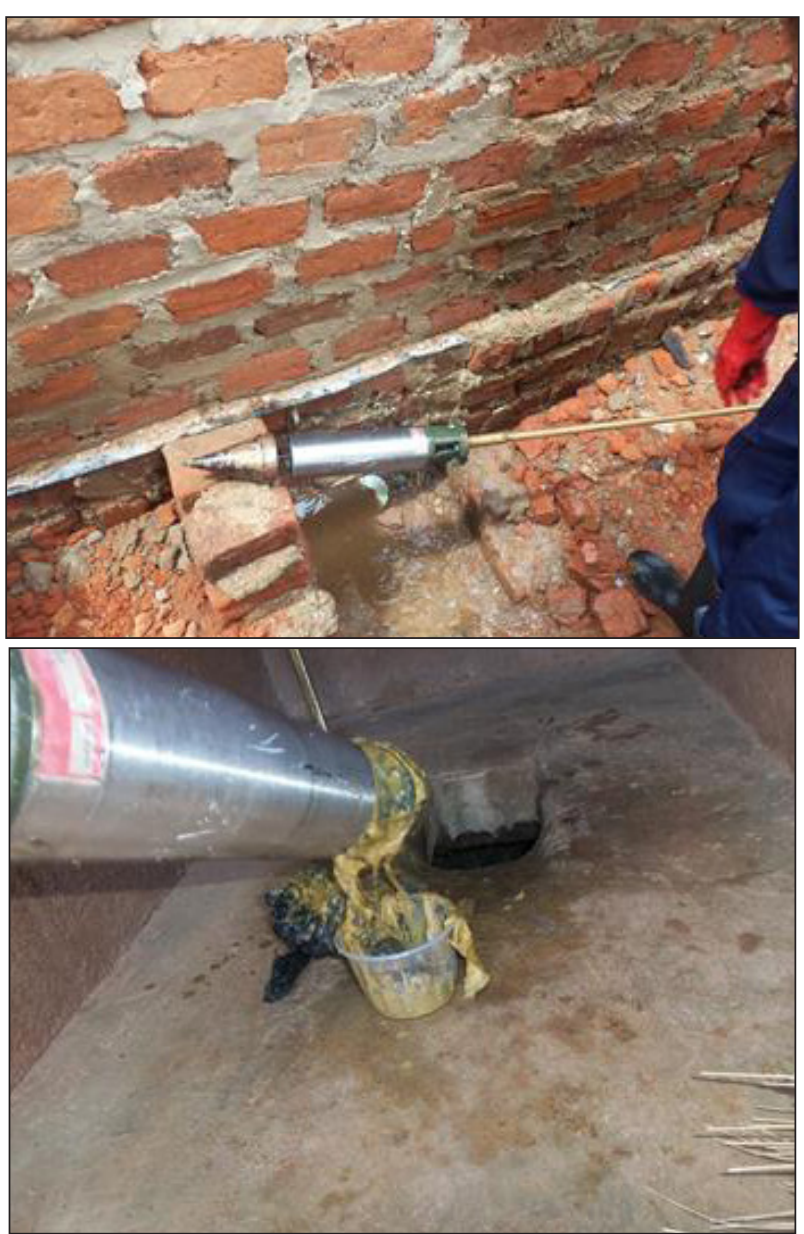

Figure 3

Pit sludge sampler (Makerere University, 2015)

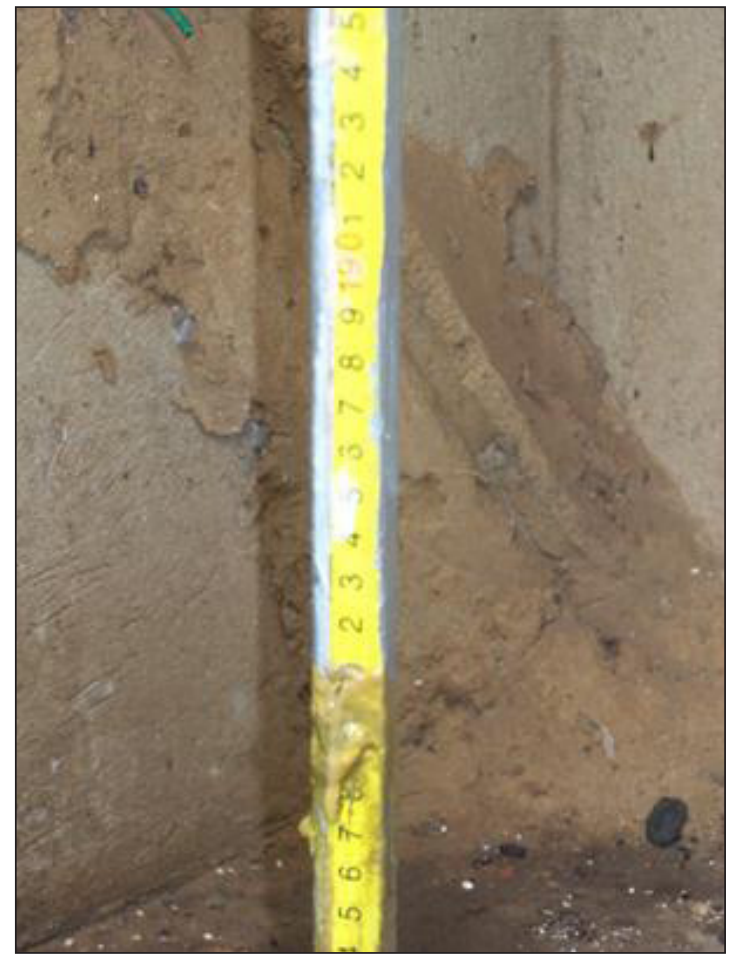

Figure 4

Depth tool with sludge markings (Makerere University, 2015) 
and this was collaborated with information in the surrounding area since most of the pit latrines in the slums are emptied at similar times. The challenge with this method was that the users were not monitoring the pit latrines and so information had to be recalled thereby giving approximations of the time since the last emptying. Triangulation checks were always included in the discussions to ensure reliable and consistent information was collected.

\section{Statistical analysis}

Correlation and descriptive statistical analyses were done to determine the averages, standard deviation and variances using GenStat Discovery Edition 4 and XLSTAT software respectively. Analysis of variance was also carried out to test for the significance of each factor in relation to the sludge accumulation rates of the pit latrines. Descriptive statistics were determined to summarize the details of the population in which the study was done. Correlation analysis was done to establish the relationship between factors and the sludge accumulation rates.

\section{RESULTS and DISCUSSION}

\section{Categories of users}

Pit latrines were divided into three different categories: private, rentals and public, based on the number of users for each category. Figure 5 shows that public pit latrines have a lower sludge accumulation rate as compared to the rentals and private pit latrines. The error bars indicate the standard deviation of the sludge accumulation rates of the pit latrines. ANOVA revealed a significant difference $(p<0.05)$ in the sludge accumulation rates between the different types of pit latrines.

Correlation analysis indicated a moderate negative correlation between the sludge accumulation rates and the number of users. This means that the sludge accumulation is affected by the number of users, and the higher the number, the lower the sludge accumulation rates (Fig. 6). This is attributed to the fact that with more users there are more microbes in the pit latrine and hence more degradation taking place (Bakare, 2014). There are also more restriction on solid waste entry in public pit latrines since they are guarded, unlike the rentals and private pits (Isunju et al., 2013).

\section{Type of material deposited in the pit latrine}

The most common materials seen in the pit latrines included: polythene bags, old clothes, blankets, sanitary pads, children's diapers, old batteries, glasses and anal cleansing material such as toilet paper and newspapers (Fig. 7). This was more common in rentals and private pit latrines than in public pit latrines. This is because public pit latrines are more restricted and guarded so that less solid waste entry occurs. In a similar study carried out in the slum areas of Kampala City, the average percentage composition of non-faecal matter was found to be $25.8 \%$ (Zziwa et al., 2016). These values were found to be as high as $40 \%$ in pit latrines that were not properly managed or used, and as low as $10 \%$ for pit latrines that were adequately or well managed.

\section{Size of the pit latrine}

The sludge accumulation rates were compared with the pit crosssectional area. A very low $R^{2}$ value $\left(R^{2}=4 \times 10^{-7}\right)$ and very low correlation $(r=-0.0063)$ indicate that the size of the pit latrine

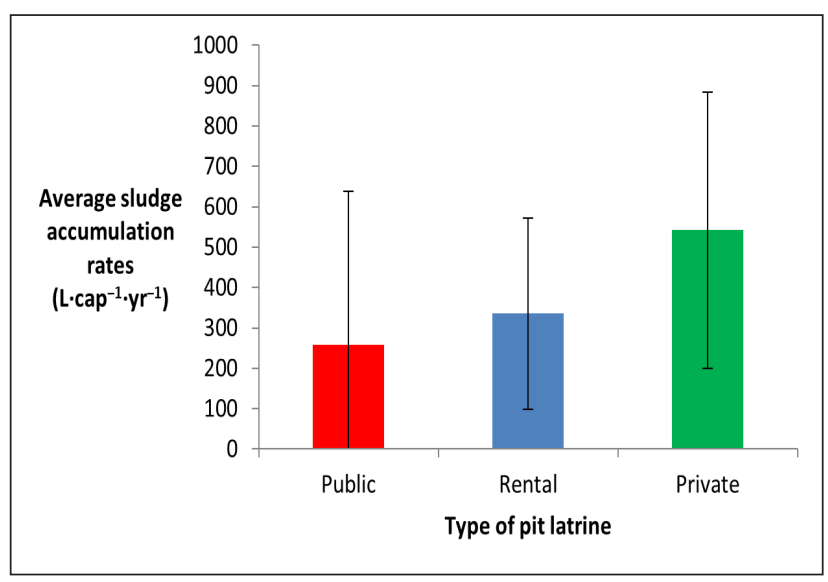

\section{Figure 5}

Trend of sludge accumulation rate with type of pit latrine

does not account for much of the variation in the filling rates of the pit latrines. In the slum areas, there is not much land for the construction of pit latrines since the plots of land are small (SRFA, 2014). Most of the pit latrines sampled had an average cross-sectional area of $3.3 \mathrm{~m}^{2}$. Most of the pit latrines were also found to be shallow with depths of approximately $1.0 \mathrm{~m}$. The reason for the shallow pits is that most of the slums are located in low-lying areas with high water tables. Pit latrines in the slums will fill up fast because of the small pit volume. The pit latrines with much bigger cross-sectional areas (area $>6 \mathrm{~m}^{2}$ ) represent the private and public pit latrines. Private pit latrines are owned by people who have lived in these areas for a long time (more than 30 years) and before the slums developed, meaning that at the time there was sufficient land to build a proper-sized pit latrine. Public pit latrines on the other hand are built by the local authorities and since they do not have similar restrictions with regard to land, the pits are much bigger and have lower filling rates.

The size of the pit latrine will also affect the frequency of emptying as those with smaller pit volumes will obviously have to be emptied much more frequently. It should also be noted that the frequency of emptying does not account for much of the variation in sludge accumulation rates of pits in slum areas. Most of the pit latrines are emptied twice a year (Fig. 8), particularly those with smaller volumes. It was also found that rental pit latrines, with $70 \%$ coverage in the slum areas, are emptied more frequently - at least twice in a year - as compared to the public and private pit latrines. This is because they have the challenge of being used as solid waste disposal sites, a practice which increases their filling rates.

\section{Geo-physical factors}

The location of the pit latrine was considered under the assumption that pit latrines located within the same area had similar geo-physical characteristics. An ANOVA was carried out for sludge accumulation rates between pit latrines located in Kampala's five different divisions (Fig. 9). There was no significant difference in the sludge accumulation rates between the different divisions $(p>0.05)$. This is because the pit latrines are lined and have no access to the environment and hence no outflow (Mara, 1984). However, there could be a level of seepage through the brick lining of the pit latrines, though in this study this was considered to be negligible in comparison to the inflow. Sludge accumulation rates in lined pit latrines are affected by inflow and user behaviour and not the geo-physical factors of the area in which they are located. 


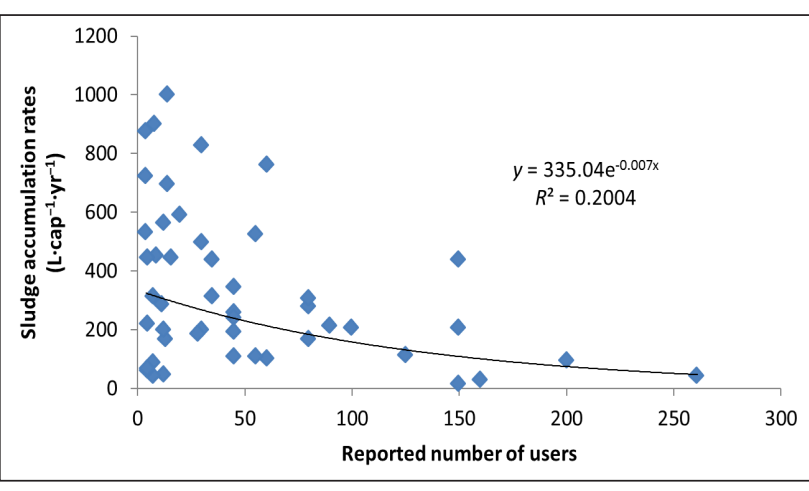

Figure 6

Sludge accumulation rates with number of users

\section{Rate of degradation using mass loss measurements}

Figure 10 shows mass losses recorded over a period of 3 months with the measurements taken weekly. It can be seen that there was a greater mass loss (ML) at a moisture level of $90-100 \%$ than $80-90 \%$. In this test, anaerobic degradation was most predominant and this was in agreement with Chaggu (2004), as there was rapid degradation at the start of the test. This was because of the readily available degradable material in the almost fresh sludge (Bakare, 2014). Greater mass loss at the $90-100 \%$ moisture level is attributed to the fact that more moisture facilitates exchange of substrate material and buffering agents, dilution of inhibitors, and the distribution/spread of microbes (Bakare et al., 2012). Sufficient water in the pit will allow increased rates of transport of soluble components and micro-organisms in the pit, allowing for optimum growth to occur (Foxon et al., 2010).

\section{CONCLUSIONS and RECOMMENDATIONS}

Based on the findings of this study, sludge accumulation rates were found to be higher in rental and private pit latrines as compared to the public pit latrines, which had more users. This was partly due to the restriction of disposal of solid waste in public pit latrines and also due to the higher degradation taking place with the greater number of microbes introduced to the pit. For rentals and private pit latrines, the greatest contributor to the filling rates of these pit latrines is the solid waste disposed of in the pit latrines.

Pit size and the frequency of emptying do not account for the variation in sludge accumulation rates in pit latrines in slum areas. However, the filling rates of pit latrines can affect how frequently a pit is emptied and the size of the pit latrine also affects by when it will fill. Rental pit latrines were emptied more frequently compared to the public and private pit latrines because they are smaller in size and being used by a large number of people, who also use them as solid waste disposal sites.

Rate of degradation of faecal matter was not found to be a challenge in the pit latrines studied since they have moisture content levels in the $90-100 \%$ range found to be optimum in the laboratory study. The difference in the sludge accumulation rates in the pit latrines was not due to a problem in the degradation reaction but rather related to an issue with what went into the pit latrine. The inflow was affected by the amount of non-faecal matter in these pit latrines which is a result of user behaviour and has an eventual effect on the filling rate.

Use of pit latrines as solid waste disposal sites is a poor culture that greatly affects the filling rates of the pit latrines and one of the recommendations of this paper is that the city

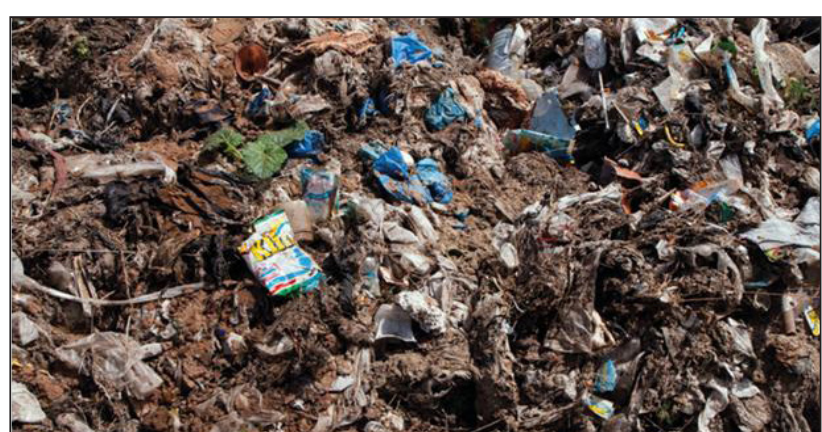

Figure 7

Non-faecal matter removed from the pit latrines during emptying (Makerere University, 2015)

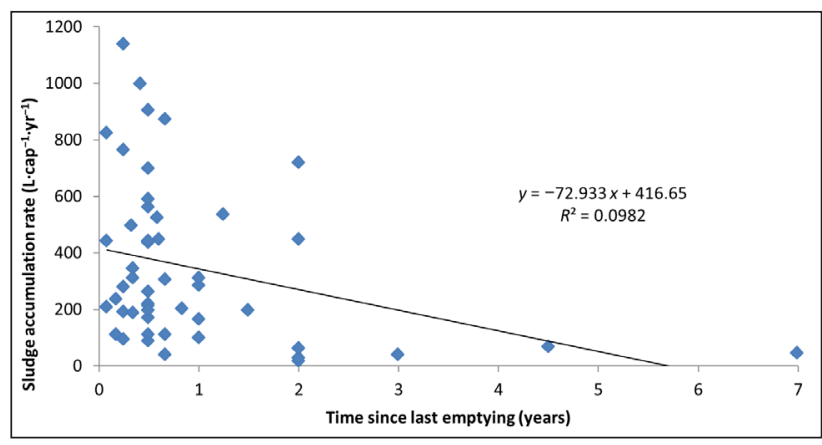

Figure 8

Relation between sludge accumulation rate and the time duration between emptying

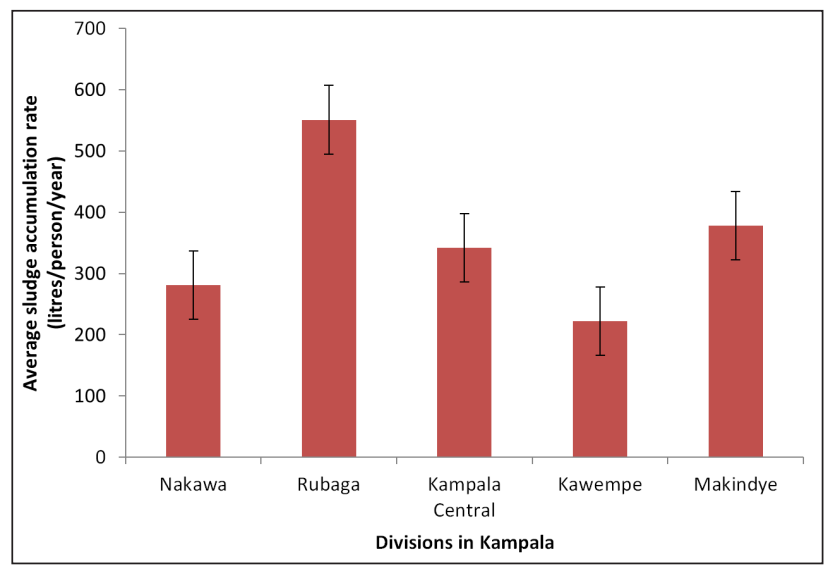

Figure 9

Sludge accumulation rates within pits in each division

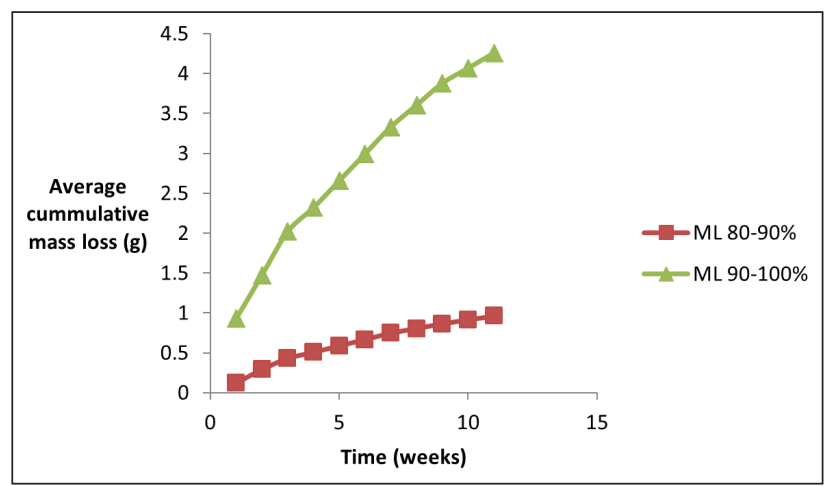

Figure 10

Variation in cumulative mass loss (ML) with time at two moisture content levels 
authorities should sensitize the public against this practice. More studies need to be done on unlined pit latrines to understand the effect of the environmental factors and soil interaction on sludge accumulation rates. This will help to accurately predict sludge accumulation rates in slum pit latrines.

\section{ACKNOWLEDGEMENTS}

This study was financed through the Sanitation Research Fund for Africa Project that was co-funded by the Water Research Commission (South Africa) and the Bill and Melinda Gates Foundation. Special thanks go to Mr Ben Byomugabe and Alfred Ahumuza for the assistance in the laboratory and the field work. Kampala City Council Authority (KCCA) and Uganda National Council for Science and Technology (UNCST) are acknowledged for the permission granted to carry out this research.

\section{REFERENCES}

BAKARE BF (2014) Scientific and management support for ventilated improved pit latrines (VIP) sludge content. PhD thesis, University of KwaZulu-Natal.

BAKARE BF, FOXON KM, BROUCKAERT CJ and BUCKLEY CA (2012) Variation in VIP latrine sludge contents. Water SA 38 (4) 479-486. http://dx.doi.org/10.4314/wsa.v38i4.2

BUCKLEY CA, FOXON KM, BROUCKAERT CJ, NWANERI C, BALBONI E and COUDERC AMD (2008) Scientific support for the design and operation of ventilated improved pit latrines (VIPs). WRC Report No. TT 357/08. Water Research Commission, Pretoria.

CHAGGU EJ (2004) Sustainable environmental protection using modified pit-latrines. $\mathrm{PhD}$ thesis, Wageningen University.

FOXON KM , NAIDOO SA, BROUCKAERT CJ, HARRISON J, PFAFF B, REMIGI E and BUCKLEY CA (2010) Can VIP additives make a difference? Proc. WISA 2016, 15-19 May 2016, Durban.

GRIMASON AM, DAVISON K, TEMBO KC, JABU GC and JACKSON $\mathrm{MH}$ (2000) Problems associated with the use of pit latrines in Blantyre, Republic of Malawi. J. R. Soc. Promo. Health. 120 (3) 175-182. http://dx.doi.org/10.1177/146642400012000307

ISABEL G, HORST A, LUTHI C, MOSLER HJ, NIWAGABA CB and TUMWEBAZE IK (2011) Where do Kampala's poor 'go'? Urban sanitation conditions in Kampala's low-income areas. Munich Personal RePEc Archive. URL: http://mpra.ub.uni-muenchen.de/45832 (Accessed 23 $3^{\text {rd }}$ August 2015)

ISRAEL GD (2013) Determining sample size. Institute of Food and Agricultural Sciences (IFAS), University of Florida, Gainesville

ISUNJU JB, ETAJAK S, MWALWEGA B, KIMWAGA R, ATEKYEREZA P, BAZEYO W and SSEMPEBWA JC (2013) Financing of sanitation services in the slums of Kampala and Dar es Salaam. Health 5 (4) 783-791. doi:10.4236/health.2013.54104. http:// dx.doi.org/10.4236/health.2013.54104

KESSIDES C (2005) The urban transition in Sub-Saharan Africa: Implications for economic growth and poverty reduction. Africa Region Working Paper Series No. 97. The World Bank, Washington DC.
KLINGEL F, MONTANGERO A, KONÉ D and STRAUSS M (2002) Fecal Sludge Management in Developing Countries: A planning manual. Water and Sanitation in Developing Countries (SANDEC). Swiss Federal Institute for Environmental Science and Technology (EAWAG), Duebendorf, Switzerland.

KULABAKO NR, NALUBEGA M and THUNVIK R (2007) Study of the impact of land use and hydrogeological settings on the shallow groundwater quality in a peri-urban area of Kampala, Uganda. Sci. Total Environ. 381 (1) 180-199. http://dx.doi.org/10.1016/j. scitotenv.2007.03.035

MARA DD (1984) The design of ventilated improved pit latrines. TAG Technical Note 13). The World Bank, Washington DC.

MONTGOMERY M (2007) Millions suffer from preventable illnesses and die every year. J. Environ. Sci. Technol. 41 17-24. http://dx.doi. org/10.1021/es072435t

NORDBERG E and WINBLAD U (1994) Urban Environmental Health and hygiene in Sub-Saharan Africa. Current African Issues 18. Nordiska Afrikainstitutet, Uppsala.

OYOO R, LEEMANS R and MOL APJ (2011) Future projections of urban waste flows and their impacts in African metropolises cities. Int. J. Environ. Res. 5 (3) 705-724.

STILL DA (2002) After the pit latrine is full... what then? Effective options for pit latrine management. Proc. Biennial Conference of the Water Institute of Southern Africa (WISA), 19-23 May 2002, Durban.

STILL DA and FOXON KM (2012) Understanding sludge accumulation in VIPs and strategies for emptying full pits. WRC Report No. 1745/1/2. Water Research Commission, Pretoria.

TORONDEL B (2010) Sanitation ventures literature review : on-site sanitation waste characteristics. London School of Hygiene and Tropical Medicine, London.

UBOS (UGANDA BUREAU OF STANDANDS) (2010) Uganda National Household Survey 2009/2010, 222. Uganda Bureau of Standands, Kampala.

UBOS (UGANDA BUREAU OF STANDANDS) (2012) Uganda Demographic and Health Survey. Uganda Bureau of Standands, Kampala.

WHO (WORLD HEALTH ORGANIZATION) (2004) Guidelines for Drinking Water Quality. WHO, Geneva.

ZZIWA A, BANADDA N, KABENGE I, WANYAMA J, KIGGUNDU N, TUMUTEGYEREIZE P, KAMBUGU R, KOMAKECH AJ, KIGOZI JB, KYAZZE F, LUGALI Y, KIMULI D, NABATEESA $S$ and NABULIME MN (2014) Baseline household survey report on pit latrine use and management practices in Kampala City. Pit sludge characterization - Makerere University Kampala. Deliverable 1, WRC Research Project Number K5/2301//11. Water Research Commission, Pretoria. 28 pp.

ZZIWA A, KABENGE I, KAYONDO H, LUGALI, Y, KAMBUGU RK and WANYAMA J (2016) Fractional content of non-faecal matter and its contribution to filling rates of pit latrines in Kampala slums. Glob. J. Eng. Sci. Res. Manag. 3 (2) 36-45. 